\title{
Inhibition of Experimental Autoimmune Encephalomyelitis in Human C-Reactive Protein Transgenic Mice Is Fc $\gamma$ RIIB Dependent
}

\author{
Xian-Zhen Hu, ${ }^{1}$ Tyler T. Wright, ${ }^{1}$ Nicholas R. Jones, ${ }^{1}$ Theresa N. Ramos, ${ }^{2}$ \\ Gregory A. Skibinski, ${ }^{1}$ Mark A. McCrory, ${ }^{1}$ Scott R. Barnum, ${ }^{2}$ and Alexander J. Szalai ${ }^{1}$ \\ ${ }^{1}$ Division of Clinical Immunology and Rheumatology, Department of Medicine, University of Alabama at Birmingham, \\ 1825 University Boulevard, SHEL 214, Birmingham, AL 35294-2182, USA \\ ${ }^{2}$ Department of Microbiology, University of Alabama at Birmingham, 1825 University Boulevard, SHEL 214, \\ Birmingham, AL 35294-2182, USA
}

Correspondence should be addressed to Alexander J. Szalai, alexszalai@uab.edu

Received 26 August 2010; Accepted 24 September 2010

Academic Editor: Noriko Isobe

Copyright (๑) 2011 Xian-Zhen Hu et al. This is an open access article distributed under the Creative Commons Attribution License, which permits unrestricted use, distribution, and reproduction in any medium, provided the original work is properly cited.

\begin{abstract}
We showed earlier that experimental autoimmune encephalomyelitis (EAE) in human C-reactive protein (CRP) transgenic mice (CRPtg) has delayed onset and reduced severity compared to wild-type mice. Since human CRP is known to engage Fc receptors and $\mathrm{Fc}_{\mathrm{c}}$ receptors are known to play a role in EAE in the mouse, we sought to determine if $\mathrm{F}_{\mathrm{c}} \gamma \mathrm{RI}, \mathrm{Fc} \gamma \mathrm{RIIb}$, or Fc $\gamma \mathrm{RIII}$ was needed to manifest human CRP-mediated protection of CRPtg. We report here that in CRPtg lacking either of the two activating receptors, $\mathrm{Fc} \gamma \mathrm{RI}$ and $\mathrm{Fc} \gamma \mathrm{RIII}$, the beneficial effects of human CRP are still observed. In contrast, if CRPtg lack expression of the inhibitory receptor Fc $\gamma$ RIIB, then the beneficial effect of human CRP is abrogated. Also, subcutaneous administration of purified human CRP stalled progression of ongoing EAE in wild-type mice, but similar treatment failed to impede EAE progression in mice lacking $\mathrm{F} c \gamma$ RIIB. The results reveal that a CRP $\rightarrow$ Fc $\gamma$ RIIB axis is responsible for protection against EAE in the CRPtg model.
\end{abstract}

\section{Introduction}

C-reactive protein (CRP) is a widely used blood marker of inflammation [1], but it is increasingly apparent that the protein plays a causal role in host defense against microbial pathogens [2] and in cardiovascular disease [3]. Furthermore, in at least three different mouse models, human CRP has been shown to protect against autoimmune disease [4-6]. Importantly, we showed that human CRP transgenic mice (CRPtg) are resistant to experimental autoimmune encephalomyelitis (EAE) [6], an animal model of multiple sclerosis (MS). Thus in CRPtg compared to wild-type mice, EAE onset was delayed, its severity was attenuated, and infiltration of encephalitogenic T-cells and monocytes/macrophages into the CNS was prevented [6]. The encephalitogenic cells with which CRP interacts to manifest protection in EAE and the mode of action of human CRP on these cells were not identified. Since human CRP binds both human and mouse Fc receptors [7-10] and because there is growing evidence that Fc receptors play a major role in controlling the emergence of EAE and other autoimmune diseases [11-15], we sought to determine if $\mathrm{F} c \gamma$ Rs were required for human CRP-mediated protection against EAE in the mouse.

Here we show that for CRPtg mice lacking expression of the activating receptors $\mathrm{F} c \gamma \mathrm{RI}$ and Fc $\gamma$ RIII, expression of human CRP delays onset and reduces severity of EAE as well as or better than it does in CRPtg with an intact $\mathrm{F} c \gamma \mathrm{R}$ repertoire. In contrast in CRPtg mice that lack expression of the inhibitory receptor, Fc $\gamma$ RIIB, no human CRP-mediated protection from EAE is observed. Likewise, administration of purified human CRP to wild-type mice with ongoing EAE prevented the disease from worsening, whereas the same treatment failed to halt worsening of EAE for mice lacking Fc $\gamma$ RIIB. The combined data suggest that human CRP $\rightarrow$ mouse Fc $\gamma$ RIIB interaction and its presumed 


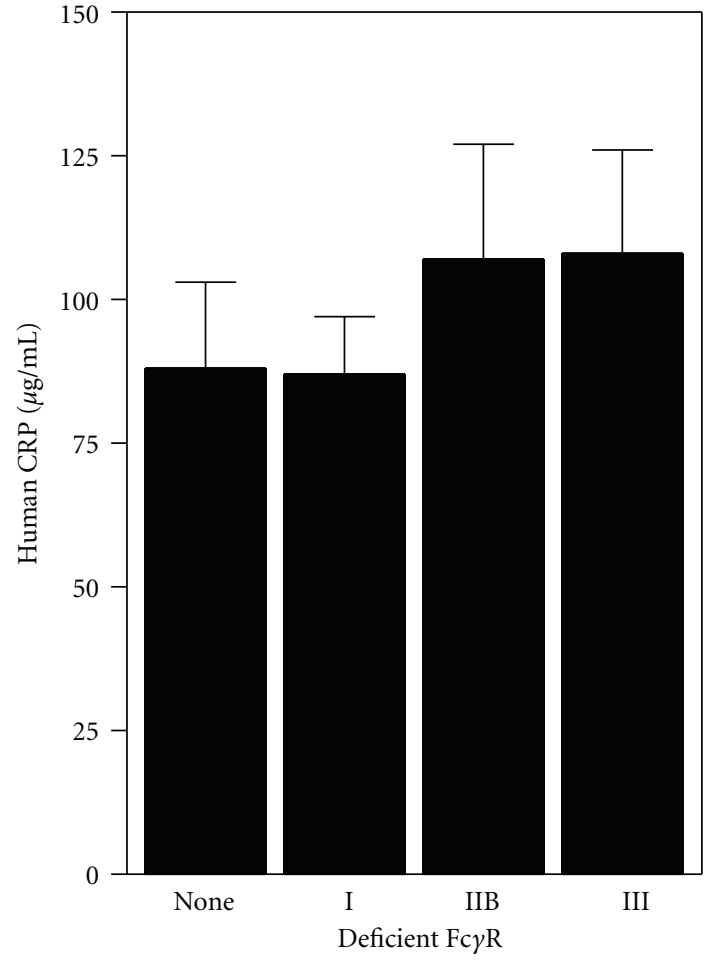

Figure 1: No effect of Fc $\gamma$ R deficiencies on expression of human CRP by CRPtg mice. Each bar and each whisker are the mean and standard deviation, respectively, for human CRP serum concentration measured for $n=5$ mice. Blood was obtained 24 hours after i.p. injection of $25 \mu \mathrm{g}$ endotoxin, and human CRP was measured by ELISA, both as described in [6].

inhibitory consequences are essential for realizing human CRP-mediated protection against EAE in the CRPtg mouse model.

\section{Materials and Methods}

2.1. Animals. CRPtg mice have been described in detail elsewhere $[16,17]$. The CRPtg strain (C57BL/6 background) carries a 31-kb human DNA fragment encoding the CRP gene, all the known cis-acting CRP regulatory elements (i.e., the entire human CRP promoter) and the CRP pseudogene [16]. Cis-acting regulatory elements within the transgene are responsible for both tissue specificity and acute phase inducibility of its expression, and the trans-acting factors required for its correct regulation are conserved from mouse to man $[16,17]$. Human CRP is expressed as an acute phase reactant in CRPtg and reaches blood levels comparable to those observed in humans with inflammatory disease (up to $500 \mu \mathrm{g} / \mathrm{mL}$ ) [17]. We showed earlier that human CRP level in the blood of CRPtg was elevated during the course of EAE [6].

CRPtg mice were mated to mutants (also C57BL/6) lacking functional expression of the genes encoding the $\alpha$ chains of Fc $\gamma$ RI (Fc $\gamma \mathrm{RI}^{-/-}$mice) [12], Fc $\gamma$ RIIB (Fc $\gamma \mathrm{RIIB}^{-/-}$ mice) [18], and Fc $\gamma$ RIII (Fc $\gamma \mathrm{RIII}^{-/-}$mice) [19]. Fc $\gamma \mathrm{R}-$ deficient versus sufficient and CRPtg versus non-CRPtg progeny were obtained in the expected Mendelian ratios each genotype appeared phenotypically normal, and none of the $\mathrm{F} c \gamma \mathrm{R}$ deficiencies significantly altered expression of human CRP (Figure 1). To identify the various genotypes, we used $C R P$ transgene-specific and $F c \gamma R$ mutation-specific PCRs, as described [12, 16-19]. All mice were fed a standard chow diet (Ralston Purina Diet) and maintained at constant humidity $(60 \pm 5 \%)$ and temperature $\left(24 \pm 1{ }^{\circ} \mathrm{C}\right)$ with a 12-hour light cycle (6 AM to $6 \mathrm{PM}$ ). All protocols were approved by the Institutional Animal Care and Use Committee at the University of Alabama at Birmingham and were consistent with the Guide for the Care and Use of Laboratory Animals published by the National Institutes of Health (NIH publication 96-01, revised 1996).

2.2. Induction of EAE. An immunodominant myelin oligodendrocyte protein (MOG) peptide was used to immunize 10-12-week-old mice, as described in [6]. On days 0 and 7 , mice received subcutaneously an injection of $150 \mu \mathrm{g}$ MOG peptide emulsified in complete Freund's adjuvant containing $500 \mu \mathrm{g}$ heat-killed Mycobacterium tuberculosis (Difco, Detroit, MI). On days 0 and 2, mice received an intraperitoneal injection of pertussis toxin (500 ng) (List Biological Laboratories, Campbell, CA). Development of EAE symptoms was monitored daily using a clinical scale ranging from 0 to 6 as follows: 0 , asymptomatic; 1, loss of tail tone; 2 , flaccid tail; 3 , incomplete paralysis of one or two hind limbs; 4, complete hind limb paralysis; 5, moribund (in which case animals were humanely euthanized); 6, dead. Mice were observed for at least 30 days, and those with a score of at least 2 for more than 2 consecutive days were deemed to have developed EAE. The maximum clinical score achieved by each animal during the 30-day observation period was used to calculate average maximum clinical score (severity) for each experimental group. To study the time-course of disease, average clinical scores were calculated and plotted daily for each group of mice, and cumulative disease index was calculated by area under the curve. When determining the average day of onset of EAE, animals that did not develop any symptoms of EAE during the 30-day period were assigned a day of onset of 31 .

2.3. Administration of Human CRP to Mice with EAE. EAE was induced as described above, and the development of symptoms was monitored. On the day their disease symptoms achieved or eclipsed a score of 2 (flaccid tail), each mouse received subcutaneously an injection of $50 \mu \mathrm{g}$ of highly purified (95\%-98\%) human CRP (US Biological, Swampscott, MA). The disease course was then followed for an additional 10 days. The CRP preparation was sodium azide-free, contained $<0.4 \mathrm{ng}$ endotoxin $/ \mathrm{mg}$ protein by Limulus amebocyte assay, and had pentameric integrity as judged by overloaded native polyacrylamide gel electrophoresis (data not shown). Control animals received $200 \mu \mathrm{g}$ of heat-denatured (boiled for 5 minutes) human CRP.

2.4. Statistical Analyses. Among genotype differences in EAE, day of onset and maximum clinical score (mean \pm sem) 


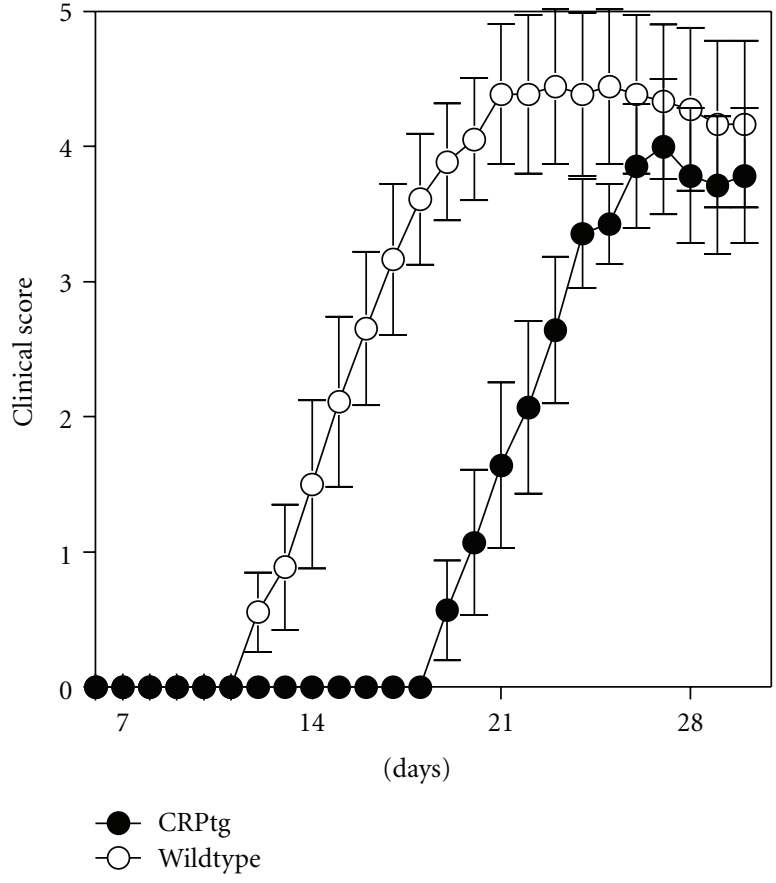

(a)

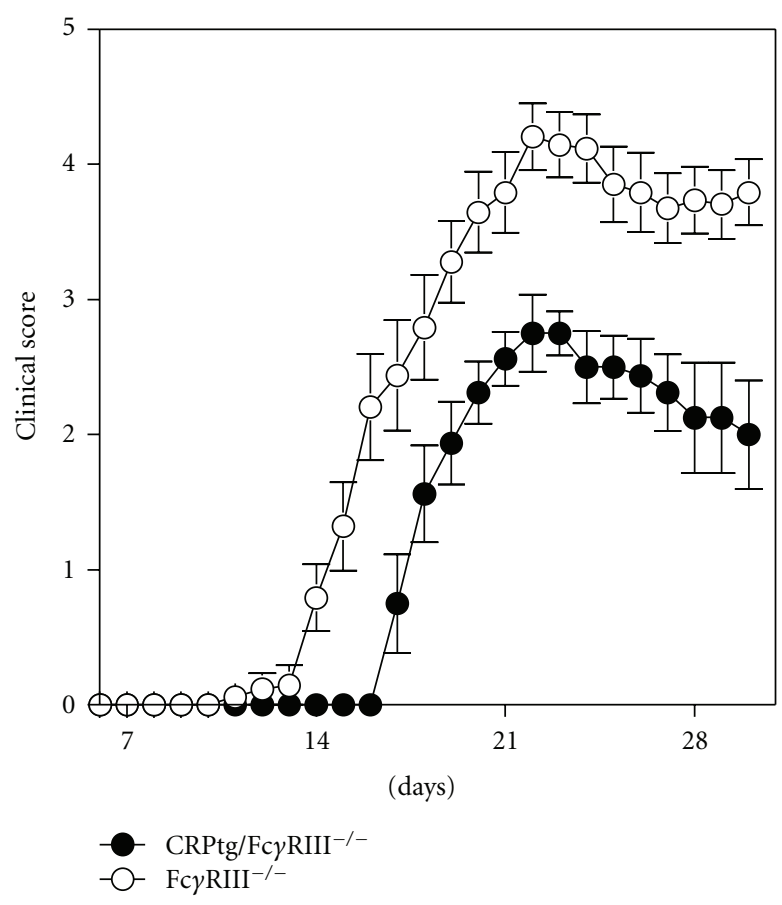

(c)

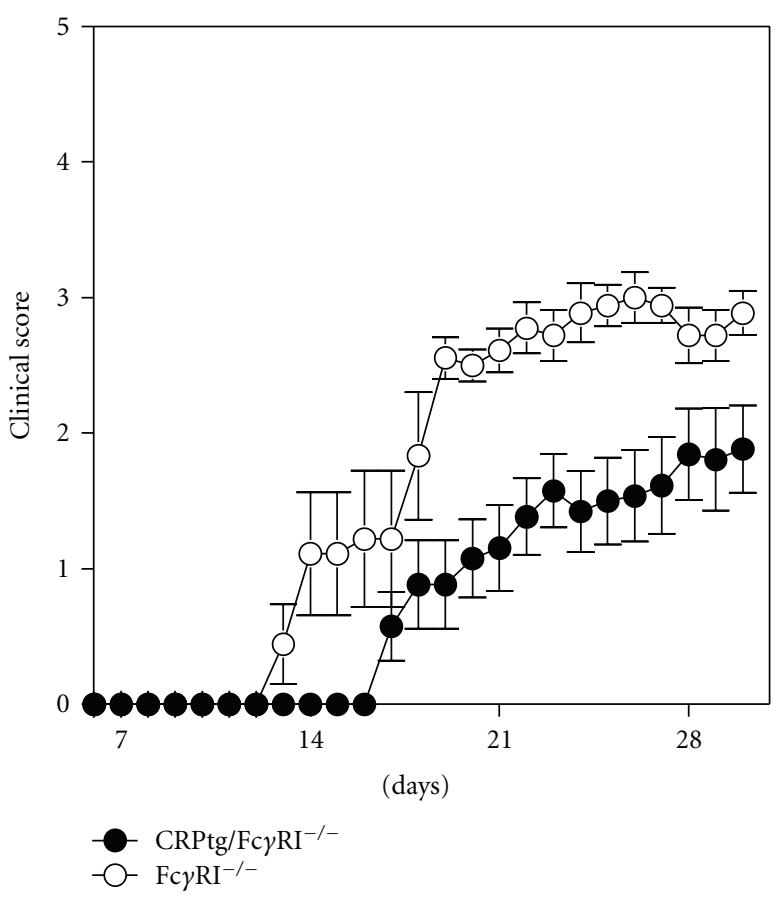

(b)

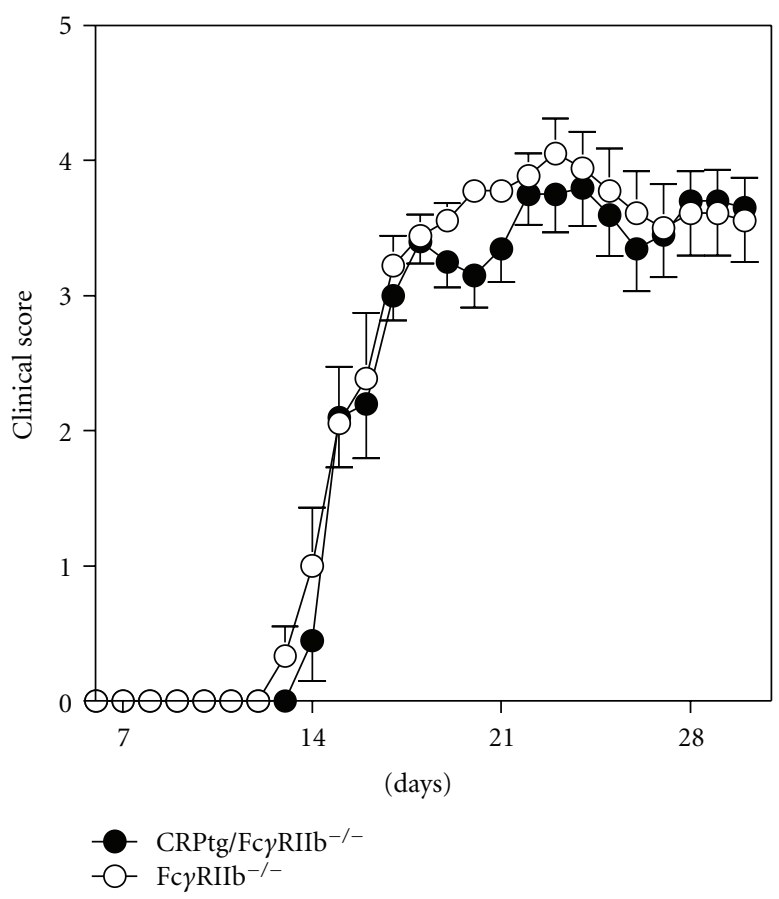

(d)

FIGURE 2: CRP-mediated protection from EAE requires Fc $\gamma$ RIIB. CRPtg versus littermate wildtype (a) or their respective counterparts lacking expression of Fc $\gamma$ RI (b), Fc $\gamma$ RIII (c), or Fc $\gamma$ RIIB (d) were injected with MOG peptide, and EAE symptoms were monitored. Presence of the CRP transgene (closed circles in each panel) delayed onset of EAE in mice with intact Fc $\gamma$ Rs (a) and delayed onset and reduced severity of EAE in mice lacking Fc $\gamma$ RI (b) or Fc $\gamma$ RIII (c). In contrast in mice lacking Fc $\gamma$ RIIB (d), expression of human CRP had no beneficial effect. See Table 1 for sample sizes and statistical analyses. 


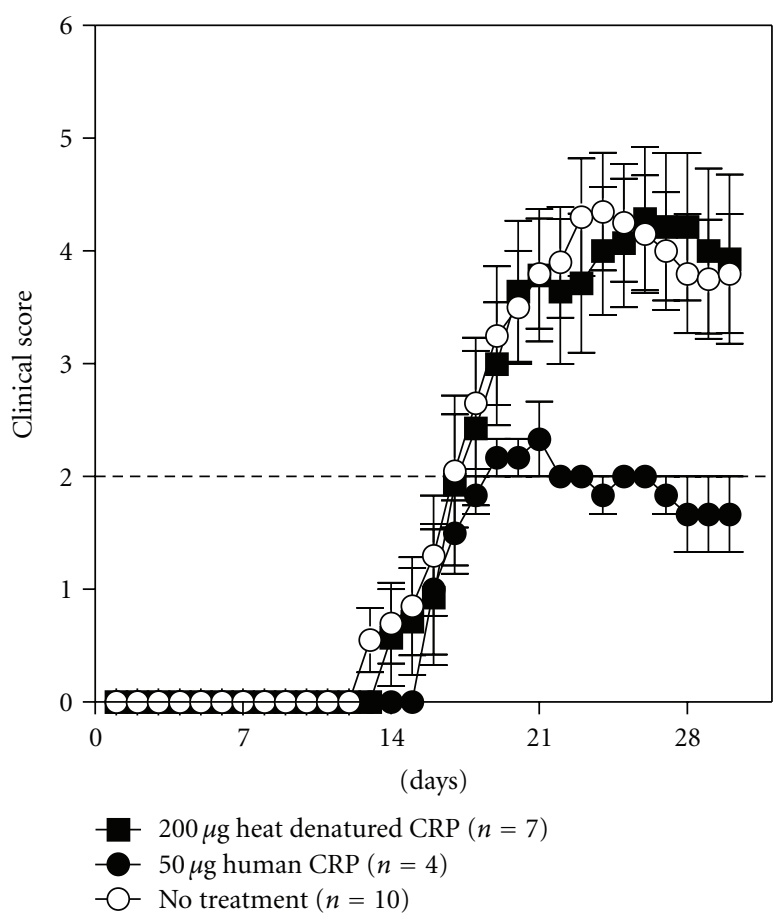

(a)

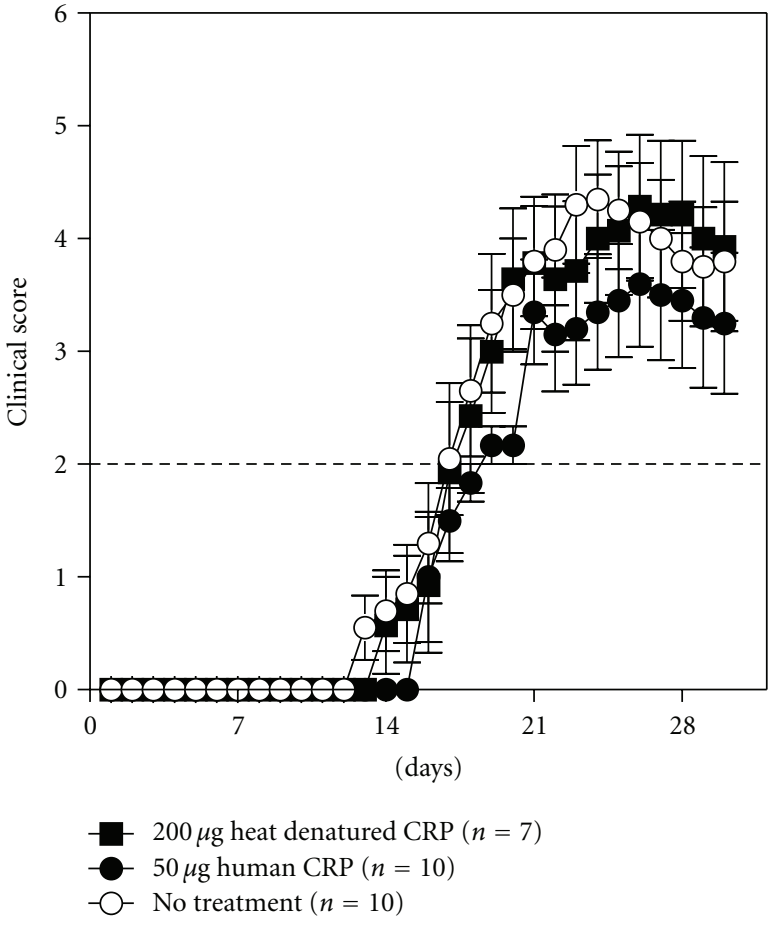

(b)

FIGURE 3: CRP treatment stalls progression of EAE in wild-type mice but not in Fc $\gamma$ RIIB $^{-/-}$mice. Wildtype (a) versus Fc $\gamma$ RIIB ${ }^{-/-}$(b) with ongoing EAE were injected with $50 \mu \mathrm{g}$ purified CRP s.c. when their clinical scores reached 2 (horizontal line), and EAE symptoms were monitored for 10 days. Controls received heat-denatured CRP.

were evaluated by one-way ANOVA and posthoc NeumanKeul's multiple comparison tests. A $P$ value less than .05 was considered significant.

\section{Results and Discussion}

As we reported previously in [6], onset of EAE was delayed by $\sim 1$ week for CRPtg compared to wild type mice (Figure 2(a) and Table $1 ; P<.001, t$-test), and this delay led to reduced cumulative disease index (Table $1 ; 32.8$ versus 46.55 ) even though average disease severity was not significantly lowered (Table 1 and Figure 2(a)). In comparison, for CRPtg that lacked expression of either Fc $\gamma$ RI or Fc $\gamma$ RIII (Figures 2(b) and 2(c), resp.), human CRP-mediated protection included not only a delay in EAE onset and a reduced cumulative disease index but also a significant reduction in disease severity (Table 1). In contrast, for CRPtg mice lacking the inhibitory receptor Fc $\gamma$ RIIB, expression of human CRP conferred no protective benefit (Table 1 and Figure $2(\mathrm{~d})$ ).

Other groups showed that human CRP administered subcutaneously to mice can reverse autoimmune- and antibody-induced inflammation $[5,20]$, a beneficial effect that reportedly requires certain $\mathrm{Fc} \gamma \mathrm{Rs}$ [20]. To test if human CRP administration might likewise protect mice from EAE and to test if $\mathrm{Fc} \gamma \mathrm{RIIB}$ was required, we administered purified human CRP to wildtype versus $\mathrm{Fc} \gamma \mathrm{RIIB}^{-/-}$mice with ongoing disease. The results are summarized in Figure 3.
We observed that for wildtype mice (Figure 3(a)) treatment with human CRP, but not treatment with heat-denatured CRP, halted progression of EAE. In contrast, no protective influence of CRP therapy was observed for $\mathrm{Fc}_{\mathrm{IIB}} \mathrm{II}^{-/}$mice (Figure 3(b)).

It has been documented that some of the in vivo activities of human CRP likely result (directly or indirectly) from the proteins ability to bind $\mathrm{F} c \gamma \mathrm{Rs}[20,21]$. Fc $\gamma$ Rs are a family of receptors of which most mammals express four main types: Fc $\gamma$ RI, Fc $\gamma$ RII, Fc $\gamma$ RIII, and Fc $\gamma$ RIV [14, 22, 23]. Each of Fc $\gamma$ RI, Fc $\gamma$ RIII, and Fc $\gamma$ RIV is comprised of a ligand binding $\alpha$-chain paired with a common $\gamma$-chain $(\operatorname{FcR} \gamma)$ that encodes an immunoreceptor tyrosine-based activation motif (ITAM) essential to propagate cell activating signals. Fc $\gamma$ RIIB on the other hand is comprised of a single $\alpha$ chain and it carries a cytoplasmic tyrosine-based inhibitory motif (ITIM) that propagates cell inhibiting signals. Various investigators have reported that human CRP binds to one or more isoforms of Fc $\gamma$ RI, Fc $\gamma$ RII, and Fc $\gamma$ RIII, in both mouse and man [7-10], and Fc $\gamma$ Rs reportedly influence EAE in the mouse $[14,24]$. Thus in CRPtg, human CRP potentially could either exacerbate EAE by binding one of the inflammation-promoting Fc $\gamma$ Rs on encephalitogenic cells or dampen EAE by binding Fc $\gamma$ RIIB. Using CRPtg mice with selective deletion of Fc $\gamma$ Rs, we were able to investigate if either capacity is realized in vivo.

Compelling evidence was obtained that the beneficial action of human CRP in mouse EAE depends mainly on 
TABLE 1: Effect of transgenic expression of human CRP on the outcome of EAE in mice lacking various Fc $\gamma$ receptors $^{\mathrm{a}}$.

\begin{tabular}{|c|c|c|c|c|c|c|}
\hline \multirow{3}{*}{ Strain } & \multirow{3}{*}{ No. mice } & \multicolumn{5}{|c|}{ Clinical measure of disease symptoms } \\
\hline & & Day of onset & & Severity & & $\mathrm{CDI}^{\mathrm{b}}$ \\
\hline & & mean \pm sem & & mean \pm sem & & \\
\hline Wildtype & 26 & $16.5 \pm 0.6$ & & $3.9 \pm 0.1$ & & 46.55 \\
\hline CRPtg & 13 & $20.3 \pm 0.8$ & $P<.001^{\mathrm{c}, \mathrm{d}}$ & $4.1 \pm 0.2$ & $\mathrm{~ns}^{\mathrm{c}}$ & 32.8 \\
\hline Fc $\gamma \mathrm{RI}^{-/-}$ & 9 & $16.3 \pm 0.9$ & $n s^{c}$ & $3.3 \pm 0.2$ & $\mathrm{~ns}^{\mathrm{c}}$ & 38.78 \\
\hline $\mathrm{Fc} \gamma \mathrm{RI}^{-/-} / \mathrm{CRPtg}$ & 13 & $21.6 \pm 1.3$ & $P<.001^{\mathrm{d}}$ & $2.7 \pm 0.1$ & $P<.01^{\mathrm{d}}$ & 18.21 \\
\hline Fc $\gamma \mathrm{RIIb}^{-/-}$ & 9 & $15.1 \pm 0.4$ & $n s^{c}$ & $4.2 \pm 0.2$ & $n s^{c}$ & 55.33 \\
\hline $\mathrm{Fc} \mathrm{RIIb}^{-/-} / \mathrm{CRPtg}$ & 10 & $15.2 \pm 0.3$ & $n s^{\mathrm{d}}$ & $4.1 \pm 0.3$ & $n s^{\mathrm{d}}$ & 51.83 \\
\hline $\mathrm{Fc} \gamma \mathrm{RIII}^{-/-}$ & 16 & $15.6 \pm 0.5$ & $n s^{c}$ & $4.4 \pm 0.2$ & $n s^{c}$ & 50.58 \\
\hline Fc $\gamma$ RIII $^{-/-} / \mathrm{CRPtg}$ & 8 & $18.4 \pm 0.5$ & $P<.05^{\mathrm{d}}$ & $3.1 \pm 0.2$ & $P<.05^{\mathrm{d}}$ & 29.63 \\
\hline
\end{tabular}

${ }^{a}$ EAE was induced with MOG peptide as described in Section 2.

${ }^{\mathrm{b}}$ Cumulative disease index (area under the curve: arbitrary units as described in Section 2).

${ }^{\mathrm{c}}$ Results of Neuman-Keuls multiple comparison test comparing indicated genotype to wildtype

${ }^{\mathrm{d}}$ Results of Neuman-Keuls multiple comparison test comparing indicated CRPtg genotype to its non-CRPtg littermates.

expression of the inhibitory receptor Fc $\gamma$ RIIB. Thus in Fc $\gamma \mathrm{RIIB}^{-/-}$mice, EAE is neither delayed nor dampened by transgenic expression of human CRP. In fact the tempo and severity of EAE in CRPtg/Fc $\gamma \mathrm{RIIB}^{-/-}$was not significantly different from that seen in wild type mice. In contrast, the human CRP-associated delay in EAE onset and attenuation of EAE symptoms were fully expressed in mice that lacked the activating receptors: Fc $\gamma$ RI or Fc $\gamma$ RIII. We did not formally rule out the possibility that Fc $\gamma$ RIV might play a role, as Fc $\gamma \mathrm{RIV}^{-/-}$mice are not available to us, but we did perform experiments with mice that lack the FcR common gamma chain $\mathrm{FcR} \gamma$, which are predicted to lack expression of $\mathrm{F} c \gamma \mathrm{RI}$, Fc $\gamma$ RIII, and Fc $\gamma$ RIV [14]. Human CRP transgenic FcR $\gamma^{-1-}$ were obviously more resistant than wildtype mice (data not shown), nevertheless the contribution of FcR $\gamma$ (and thus Fc $\gamma$ RIV) to human CRP-mediated resistance to EAE remains unclear because $\mathrm{FcR} \gamma^{-1-}$ mice per se are intrinsically very resistant to EAE [24]. Thus in their sum the data suggest that the EAE-protective effect of human CRP in the CRPtg mouse depends largely on the availability/expression of Fc $\gamma$ RIIB. Presumably by binding Fc $\gamma$ RIIB, human CRP expressed endogenously during the course of disease dampens the activation state of encephalitogenic (Fc $\gamma$ RIIB-expressing) cells in CRPtg. Likewise, in nontransgenic mice, exogenously administered human CRP has the same effect as long as Fc $\gamma$ RIIB is present.

\section{Conclusions}

For CRPtg mice, transgene-expressed human CRP inhibits EAE, and this beneficial action requires Fc $\gamma$ RIIB. If as in CRPtg with EAE, a protective $\mathrm{CRP} \rightarrow \mathrm{Fc} \gamma \mathrm{RIIB}$ axis exists in humans with MS, then CRP administration might be beneficial in the clinical treatment of patients with MS. Ongoing efforts in our laboratory are aimed at identifying the CRP-responsive Fc $\gamma$ RIIB-expressing encephalitogenic cell(s) involved in this action, which we posit to be dendritic cells [25].

\section{Acknowledgments}

The paper described herein was funded by a research Grant from the National Multiple Sclerosis Society (RG 3216-A5 to AJS and SRB), by training Grants from the National Institutes of Health (T32 AI07051 to TNR and T32 AR07450 to NRJ), and the Howard Hughes Med-Grad Fellowship Program at UAB (to TTW).

\section{References}

[1] C. Gabay and I. Kushner, "Acute-phase proteins and other systemic responses to inflammation," New England Journal of Medicine, vol. 340, no. 6, pp. 448-454, 1999.

[2] A. J. Szalai, "The antimicrobial activity of C-reactive protein," Microbes and Infection, vol. 4, no. 2, pp. 201-205, 2002.

[3] R. J. Bisoendial, S. M. Boekholdt, M. Vergeer, E. S. G. Stroes, and J. J. P. Kastelein, "C-reactive protein is a mediator of cardiovascular disease," European Heart Journal, vol. 31, no. 17, pp. 2087-2095, 2010.

[4] A. J. Szalai, C. T. Weaver, M. A. McCrory et al., "Delayed lupus onset in $(\mathrm{NZB} \times \mathrm{NZW}) \mathrm{F} 1$ mice expressing a human $\mathrm{C}$ reactive protein transgene," Arthritis and Rheumatism, vol. 48, no. 6, pp. 1602-1611, 2003.

[5] W. Rodriguez, C. Mold, L. L. Marnell et al., "Prevention and reversal of nephritis in MRL/lpr mice with a single injection of C-reactive protein," Arthritis and Rheumatism, vol. 54, no. 1, pp. 325-335, 2006.

[6] A. J. Szalai, S. Nataf, X.-Z. Hu, and S. R. Barnum, "Experimental allergic encephalomyelitis is inhibited in transgenic mice expressing human C-reactive protein," Journal of Immunology, vol. 168, no. 11, pp. 5792-5797, 2002.

[7] L. L. Marnell, C. Mold, M. A. Volzer, R. W. Burlingame, and T. W. Du Clos, "C-reactive protein binds to Fc $\gamma$ RI in transfected COS cells," Journal of Immunology, vol. 155, no. 4, pp. 21852193, 1995.

[8] M.-P. Stein, C. Mold, and T. W. Du Clos, "C-reactive protein binding to murine leukocytes requires Fc $\gamma$ receptors," Journal of Immunology, vol. 164, no. 3, pp. 1514-1520, 2000.

[9] C. Mold, H. D. Gresham, and T. W. Du Clos, "Serum amyloid $\mathrm{P}$ component and C-reactive protein mediate phagocytosis 
through murine Fc $\gamma$ Rs," Journal of Immunology, vol. 166, no. 2, pp. 1200-1205, 2001.

[10] J. Lu, L. L. Marnell, K. D. Marjon, C. Mold, T. W. Du Clos, and P. D. Sun, "Structural recognition and functional activation of Fc $\gamma$ R by innate pentraxins," Nature, vol. 456, no. 7224, pp. 989-992, 2008.

[11] S. Kleinau, P. Martinsson, and B. Heyman, "Induction and suppression of collagen-induced arthritis is dependent on distinct Fc $\gamma$ receptors," Journal of Experimental Medicine, vol. 191, no. 9, pp. 1611-1616, 2000.

[12] N. Barnes, A. L. Gavin, P. S. Tan, P. Mottram, F. Koentgen, and P. M. Hogarth, "Fc $\gamma$ RI-deficient mice show multiple alterations to inflammatory and immune responses," Immunity, vol. 16, no. 3, pp. 379-389, 2002.

[13] K. G. C. Smith and M. R. Clatworthy, "Fc $\gamma$ RIIB in autoimmunity and infection: evolutionary and therapeutic implications," Nature Reviews Immunology, vol. 10, no. 5, pp. 328343, 2010.

[14] A. J. Szalai and S. R. Barnum, "Fc receptors and the common $\gamma$-chain in experimental autoimmune encephalomyelitis," Journal of Neuroscience Research, vol. 75, no. 5, pp. 597-602, 2004.

[15] M. I. Iruretagoyena, C. A. Riedel, E. D. Leiva, M. A. Gutiérrez, S. H. Jacbobelli, and A. M. Kalergis, "Activating and inhibitory Fcy receptors can differentially modulate $\mathrm{T}$ cell-mediated autoimmunity," European Journal of Immunology, vol. 38, no. 8, pp. 2241-2250, 2008.

[16] G. Ciliberto, R. Arcone, E. F. Wagner, and U. Rüther, "Inducible and tissue-specific expression of human C-reactive protein in transgenic mice," EMBO Journal, vol. 6, no. 13, pp. 4017-4022, 1987.

[17] A. J. Szalai and M. A. McCrory, "Varied biologic functions of C-reactive protein: lessons learned from transgenic mice," Immunologic Research, vol. 26, no. 1-3, pp. 279-287, 2002.

[18] T. Takai, M. Ono, M. Hikida, H. Ohmori, and J. V. Ravetch, "Augmented humoral and anaphylactic responses in Fc $\gamma$ RIIdeficient mice," Nature, vol. 379, no. 6563, pp. 346-349, 1996.

[19] W. L. W. Hazenbos, J. E. Gessner, F. M. A. Hofhuis et al., "Impaired IgG-dependent anaphylaxis and Arthus reaction in Fc $\gamma$ RIII (CD16) deficient mice," Immunity, vol. 5, no. 2, pp. 181-188, 1996.

[20] W. Rodriguez, C. Mold, M. Kataranovski et al., "C-reactive protein-mediated suppression of nephrotoxic nephritis: role of macrophages, complement, and Fc $\gamma$ receptors," Journal of Immunology, vol. 178, no. 1, pp. 530-538, 2007.

[21] D. Xing, F. G. Hage, Y.-F. Chen et al., "Exaggerated neointima formation in human C-reactive protein transgenic mice is IgG Fc receptor type I (Fc $\gamma \mathrm{RI})$-dependent," American Journal of Pathology, vol. 172, no. 1, pp. 22-30, 2008.

[22] F. Nimmerjahn, P. Bruhns, K. Horiuchi, and J. V. Ravetch, "Fc $\gamma$ RIV: a novel FcR with distinct IgG subclass specificity," Immunity, vol. 23, no. 1, pp. 41-51, 2005.

[23] F. Nimmerjahn and J. V. Ravetch, "Fcy receptors: old friends and new family members," Immunity, vol. 24, no. 1, pp. 1928, 2006.

[24] A. J. Szalai, X. Hu, C. Raman, and S. R. Barnum, "Requirement of the Fc receptor common $\gamma$-chain for $\gamma \delta \mathrm{T}$ cellmediated promotion of murine experimental autoimmune encephalomyelitis," European Journal of Immunology, vol. 35, no. 12, pp. 3487-3492, 2005.

[25] R. Zhang, L. Becnel, M. Li, C. Chen, and Q. Yao, "C-reactive protein impairs human $\mathrm{CD} 14+$ monocyte-derived dendritic cell differentiation, maturation and function," European Journal of Immunology, vol. 36, no. 11, pp. 2993-3006, 2006. 


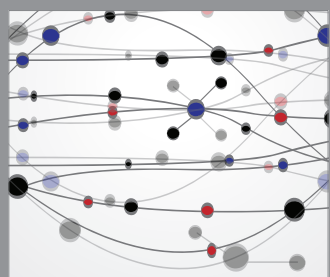

The Scientific World Journal
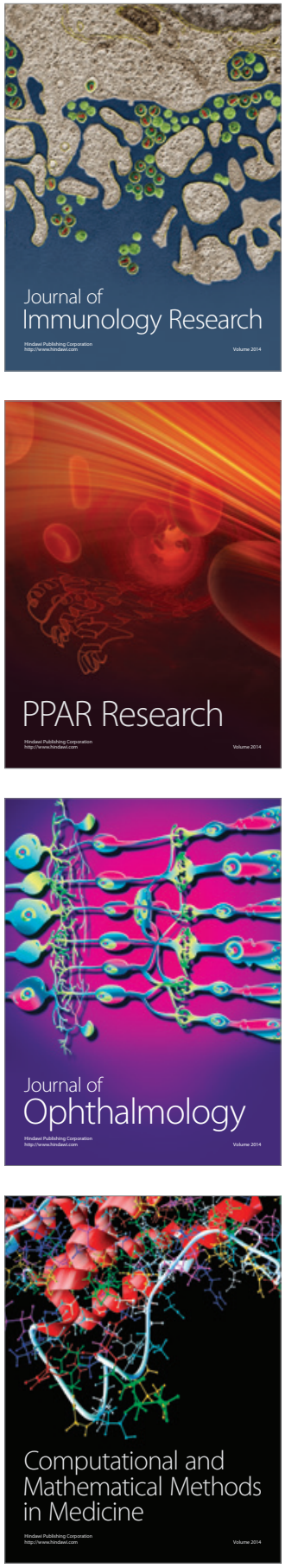

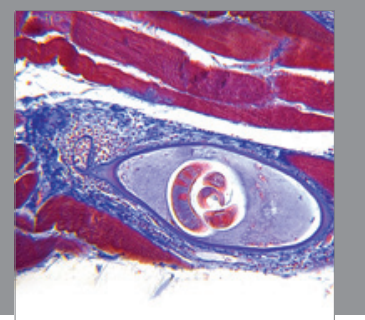

Gastroenterology

Research and Practice
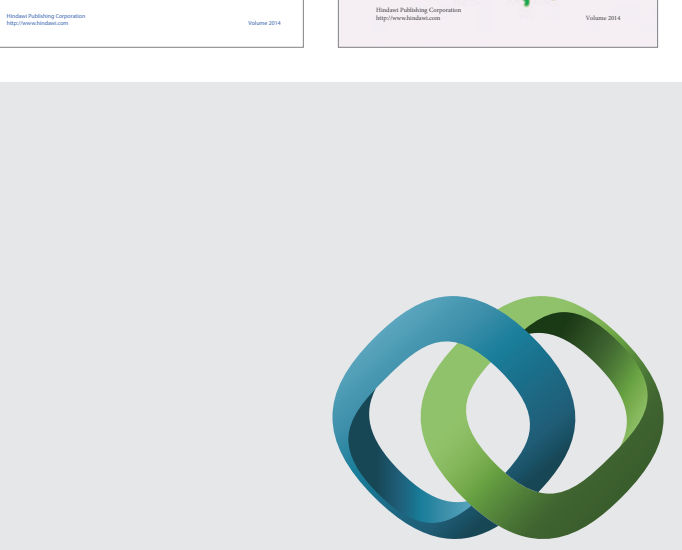

\section{Hindawi}

Submit your manuscripts at

http://www.hindawi.com
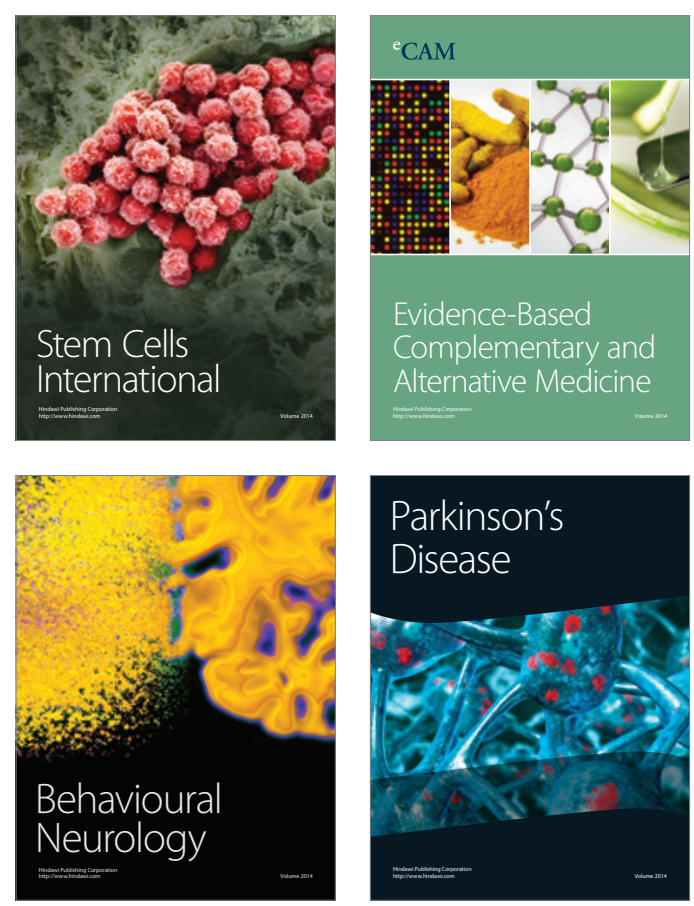

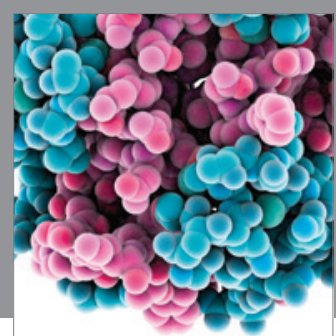

Journal of
Diabetes Research

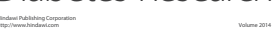

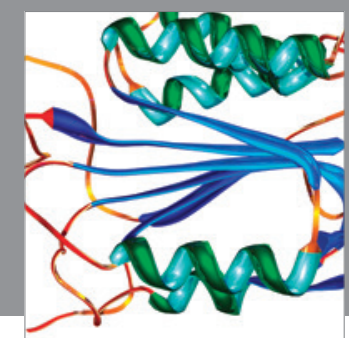

Disease Markers
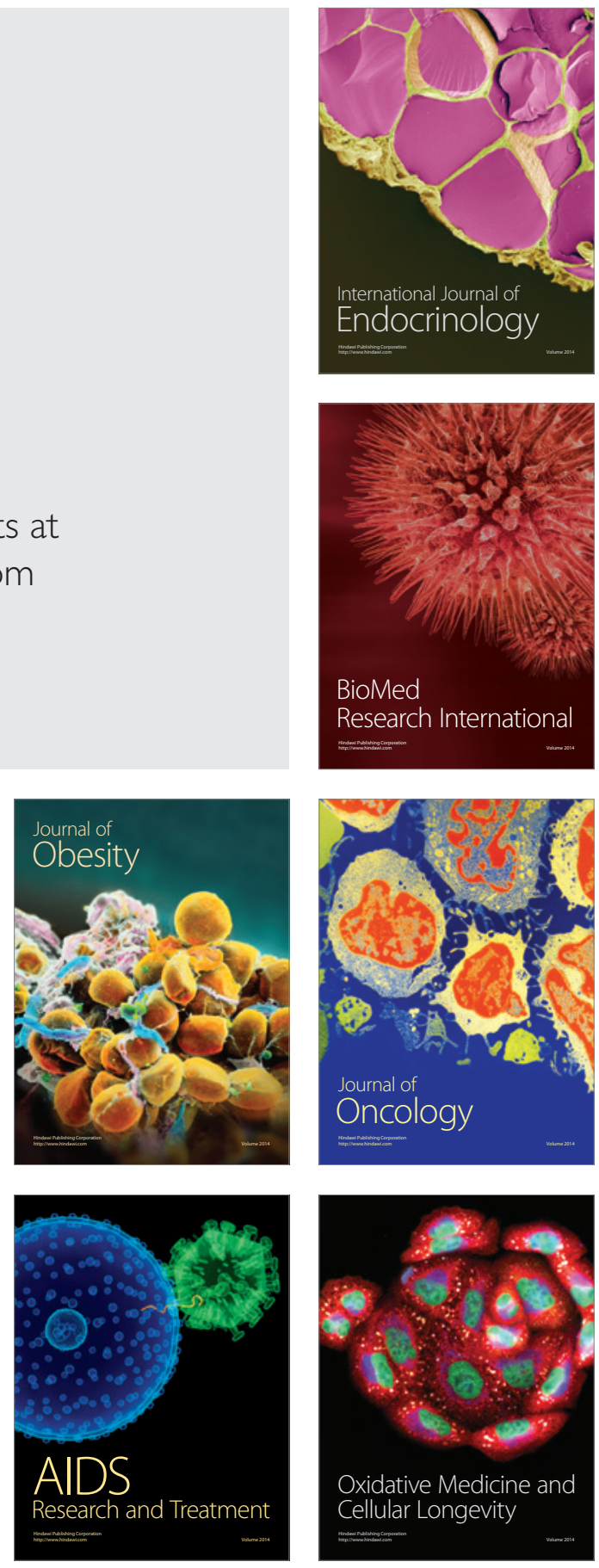